\title{
Takayasu Disease in Niger: About Three Cases and Literature Review
}

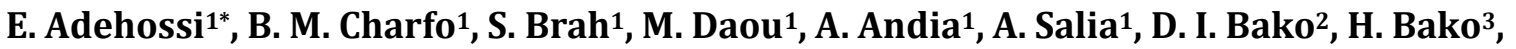 \\ H. Idrissa ${ }^{3}$, R. Sani ${ }^{4}$
}

${ }^{1}$ Department of Internal Medicine, Hôpital National de Niamey, Niamey, Niger

${ }^{2}$ Department of Radiology, Hôpital National de Niamey, Niamey, Niger

${ }^{3}$ Department of Cardiology, Hôpital National de Niamey, Niamey, Niger

${ }^{4}$ Department of General Surgery, Hôpital National de Niamey, Niamey, Niger

Email: *eadehossi@yahoo.fr

How to cite this paper: Adehossi, E., Charfo, B.M., Brah, S., Daou, M., Andia, A., Salia, A., Bako, D.I., Bako, H., Idrissa, H. and Sani, R. (2019) Takayasu Disease in Niger: About Three Cases and Literature Review. Open Journal of Internal Medicine, 9, 129-140.

https://doi.org/10.4236/ojim.2019.94018

Received: September 24, 2019

Accepted: November 12, 2019

Published: November 15, 2019

Copyright (อ 2019 by author(s) and Scientific Research Publishing Inc. This work is licensed under the Creative Commons Attribution International License (CC BY 4.0).

http://creativecommons.org/licenses/by/4.0/

\begin{abstract}
Takayasu arteritis is a chronic, idiopathic, and inflammatory disease that primarily affects large vessels, such as the aorta and its main branches. Much of the literature describing Takayasu arteritis has originated from Asian countries, and the disease was once thought to be restricted to these regions. During the past few decades, patients with Takayasu arteritis have been increasingly recognized in Africa. We report three first cases of Takayasu's arteritis in Niger by focusing on epidemiological clinical radiological and therapeutic aspects. Of the three patients, two were women and the age of onset was 27 years in one case and 33 years in the other two cases. Clinically, abolition of at least one peripheral pulse was constantly observed. We find a predominance of the involvement of the supra-aortic trunks in 3 cases and less of the abdominal aortic involvement in 1 case. Moreover, our series is distinguished by a case revealed by a stroke in a male subject. Corticosteroids were successful with clinical improvement and stabilization of the disease in the short and medium term. The revascularization performed in two of the patients. Tayasu arteritis is uncommon disease that must be evoked before a symptomatology non-specific coaches and lead to check the pulse. Ischemic complications are already present at the time of diagnosis. We have found a high frequency of arterial thrombosis in our series.
\end{abstract}

\section{Keywords}

Takayasu Arteritis, Niamey, Niger

\section{Introduction}

Takayasu's disease is arteritis, often granulomatous, predominantly affecting the 
aorta and/or its major branches. [1]. The disease has a worldwide distributional though it occurs more commonly in Asia [2].

Much of the literature describing Takayasu's arteritis has originated from Asian countries, and the disease was once thought to be restricted to these regions. During the past few decades, patients with Takayasu's arteritis have been increasingly recognized in Africa, Western Europe, and North America [3]. The estimated incidence rate is 2.6 cases per million persons per year. The exact incidence of Takayasu arteritis in Africa is not known.

This chronic inflammation leads to the development of stenosis, thromboses and sometimes arterial aneurysms.

The diagnosis is based on clinical arguments and vascular imaging. It is clinically characterized by two phases, the first one nonspecific and the other vascular depending on the type and site of the vascular inflammatory lesion [4]. These two phases can be separated by an asymptomatic period or were intricate. There is no specific diagnostic marker for Takayasu's disease. The different methods of modern imaging are currently a great help for the diagnosis. The magnetic resonance angio-imaging and more recently of the positron-scanner tomography had an interesting contribution. These imaging techniques could also be interesting for the follow-up of patients.

The treatment of Takayasu's disease is medical. It aims to treat the inflammatory part of the disease and in some cases revascularization by angioplasty or surgery. Medical treatment is based on corticosteroid therapy, which is often associated with immunosuppressive drugs in severe, refractory or corticoid-dependent forms. Recently biotherapies such as anti-tumor necrosis factor- $\alpha$ and anti-RIL6 have very promising results in the refractory forms.

We report three cases of Takayasu arteritis collected at the Internal Medicine Department of Hôpital National of Niamey (HNN).

\section{Observation 1}

A 28-year-old woman who had a sister followed for a cerebral aneurysm, consults in May 2013 for headaches and vertigo.

The symptomatology began in November 2012 with the appearance of pulsatile frontal headaches radiating in the temples. This symptomatology was accompanied by tearing, left blepharospasm and a decrease in left visual acuity spontaneously resolving within two weeks. She had a feverish feeling and moderate weight loss.

The examination shows an abolition of radial pulse with fever $\left(38.2^{\circ} \mathrm{C}\right)$. The blood pressure should not be taken on both arms and was 110/60 $\mathrm{mmHg}$ on the pelvic limbs. There is murmur on subclavian arteries auscultation.

Leukocytosis was $11,600 / \mathrm{mm}^{3}$ with a sedimentation rate at $91 \mathrm{~mm}$ and CRP at $34 \mathrm{mg} / 1$.

After medevac in Morocco, a Doppler ultrasound of supra aortic trunks revealed thrombosis of the left common carotid artery and an arteriography and 
angio-CT scan confirmed left common carotid thrombosis, right common carotid stenosis, very narrow stenosis of brachiocephalic artery, stenosis of both subclavian arteries, but left and right vertebral arteries were patent (Figure 1 \& Figure 2).

The diagnosis of Takayasu's disease was based on the following criteria: age less than 40 years, abolition of radial pulse, murmur of subclavian arteries and arteriographic abnormalities.

After a syncopal episode, she was operated on urgently for bi-carotid bypass surgery. She was given prednisone at $1 \mathrm{mg} / \mathrm{kg} / \mathrm{day}$ and subsequently underwent dilatation of the subclavian arteries.

She is regularly followed in the department of internal medicine. She received a second medevac in 2018 for a pregnancy. She was followed in Morocco until the birth of the child $12^{\text {th }}$ march 2019 . She is currently under clopidogrel $75 \mathrm{mg}$ and deflazacort $7.5 \mathrm{mg} / \mathrm{J}$.

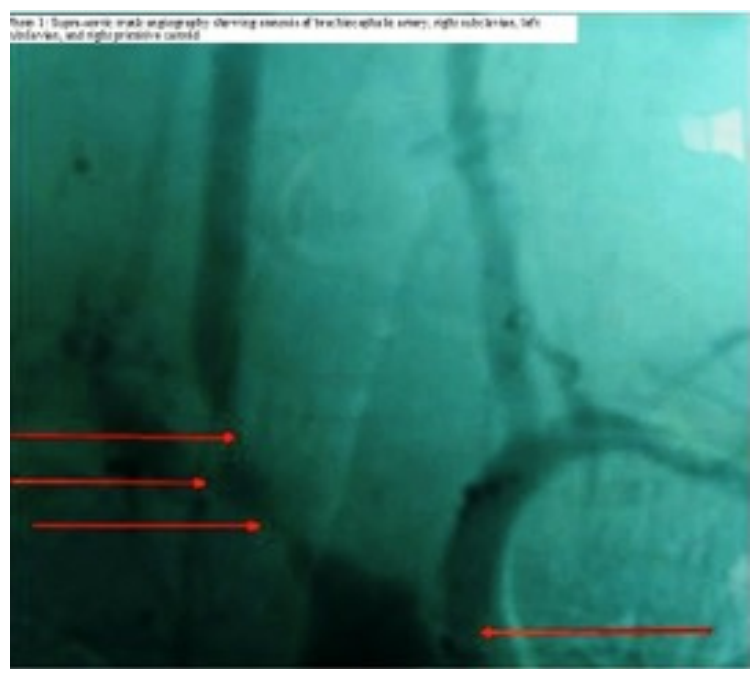

Figure 1. Supra-aortic trunk angiography showing stenosis of brachiocephalic artery, right subclavian, left subclavian, and right primitive carotid.

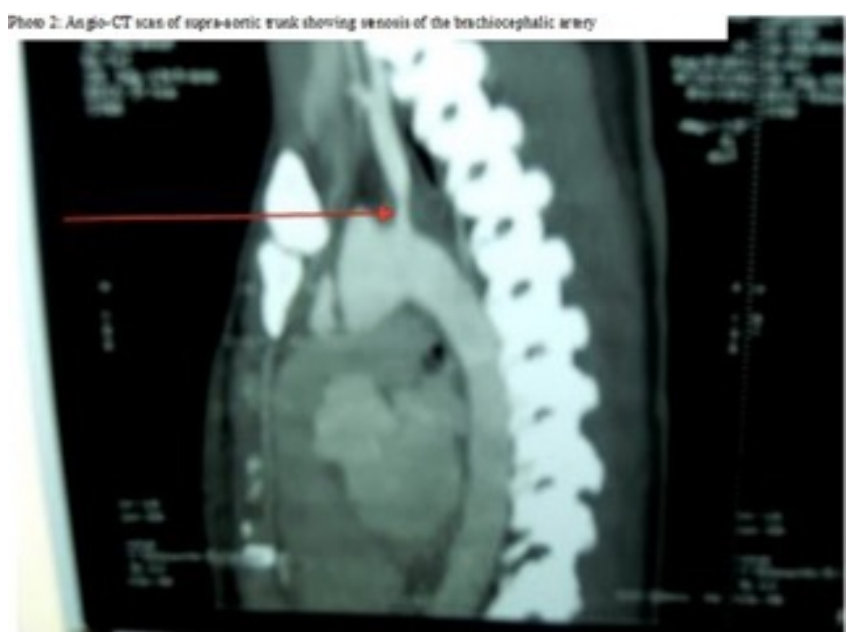

Figure 2. Angio-CT of supra-aortic trunk showing stenosis of the brachiocephalic artery. 


\section{Observation $\mathrm{N}^{\circ} 2$}

A 33-year-old patient with a history of hospitalization in psychiatry, 4 months ago for behavioral disorders and detoxification with cannabis, arrives at emergencies for a sudden right hemiplegia in October 2016.

At admission, the examination noted a conscious patient with a blood pressure of 120/85 mm Hg on the upper right limb and both lower limbs. The blood pressure should not be taken in the upper left arm with an abolition of the humeral and radial pulse.

Auscultation of the carotid artery was normal.

The neurological examination found proportional right hemiplegia and Broca aphasia. The NIH stroke score was estimated at 11.

The sedimentation rate was $123 \mathrm{~mm}$ and C protein reactive at $44.71 \mathrm{mg} / \mathrm{l}$.

The blood count showed anemia at $10.5 \mathrm{~g} / \mathrm{dl}$.

Blood ionogram, fasting blood glucose, total cholesterol, LDL cholesterol, HDL cholesterol, TP, TCA were normal. HIV serology, syphilitic serology, intradermal reaction to tuberculin was negative.

The research of anti-nuclear antibodies was negative.

The cerebral CT scan and the cerebral CT scan angiography showed an ischemic stroke of the deep territory of the left middle cerebral artery.

Doppler ultrasound was normal.

Doppler echo of the supra-aortic trunks showed atheromatous of the left common carotid without hemodynamic repercussions.

A brain scan showed hypodensity suggestive of ischemic stroke in the left middle cerebral artery territory (Figure 3 ).

CT-scan angiography of supra-aortic and thoracoabdominal trunks showed multiple arterial thrombosis: left subclavian, both pulmonary arteries and right renal artery.

It also shows obstruction of the axillary and left brachial arteries.

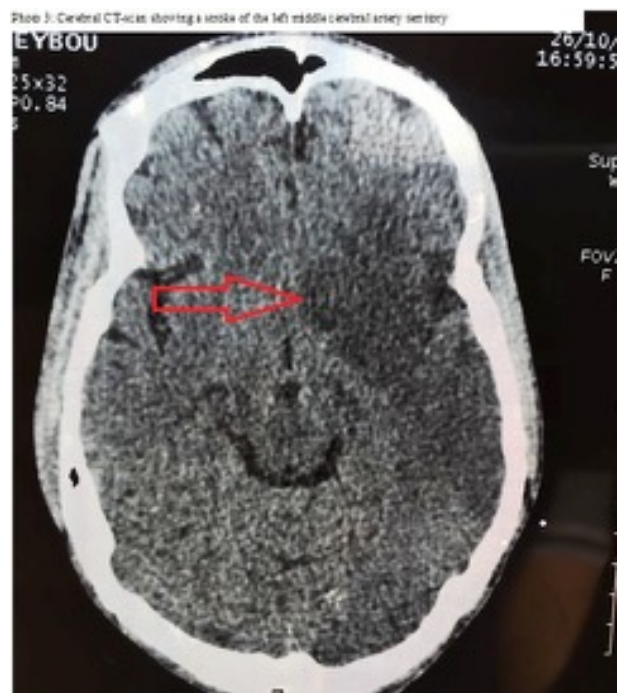

Figure 3. Cerebral CT-scan showing a stroke of the left middle cerebral artery territory. 
Takayasu disease complicated by ischemic stroke is diagnosed based on the criteria of the ACR including age $<40$ years, anisophygmy, anisotension and thrombosis of the left subclavian artery.

The patient was given prednisone $1 \mathrm{mg} / \mathrm{kg} /$ day combined with $160 \mathrm{mg} /$ day of aspirin and $20 \mathrm{mg}$ of atorvastatin. Functional motor rehabilitation has also been introduced.

The evolution at one month was characterized by a partial functional motor recovery at the right upper limb with a muscular force that increases to $3 / 5$. Physical examination note a reappearance of radial pulse and the blood pressure in the left arm, however, we still have anisophygmy with a right radial pulse: 104 bpm against $85 \mathrm{bpm}$ on the left.

The patient died 3 months after diagnosis due to unconsciousness.

\section{Observation $\mathrm{N}^{\circ} 3$}

This is a patient, 33, years old married and mother of 4 children who has consulted several times since March 2005 for multiple pain with anxiety and feverish feeling, night sweating, weight loss, anorexia, asthenia and headaches.

In January 2006, it was found, an absence of right radial pulse.

The sedimentation rate was greater than $100 \mathrm{~mm}$ with an anemia at $8 \mathrm{~g} / \mathrm{dl}$.

A Doppler ultrasound of the vessels showed stenosis of the right humeral artery and the patient was put on aspirin. She was evacuated to Morocco for further investigations in February 2006 where arteriography showed total stenosis of the humeral artery, stenosis of the left subclavian but the aorta and supra-cardiac trunks were normal (Figure 4). The diagnosis of Takayasu's disease was based on the criteria of the ACR: age below 40 years, asymmetry of the pulse and arteriography anomalies.

Corticosteroid treatment based on $1 \mathrm{mg} / \mathrm{kg} / \mathrm{day}$ of prednisone was initiated in combination with antiplatelet agent and anticoagulation.

The evolution was complicated by ischemia of the last phalanx of the right index finger and led to the amputation of the latter, followed by arterial dilatation.

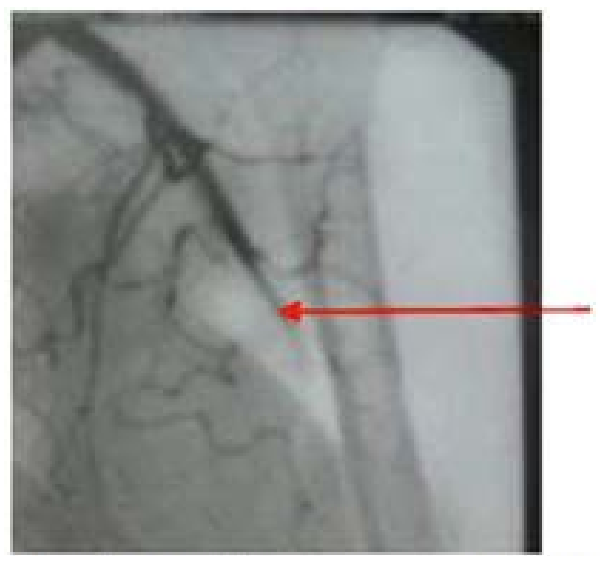

Figure 4. Angiography showing stenosis of the left humeral artery and extensive networks of collateral vessels. 
In 2012, another endovascular dilatation with stent placement in the left axillary artery was performed.

She is currently being followed in neurology department for pain related to thalamic disease. Her treatment now was amitriptyline $75 \mathrm{mg} / \mathrm{J}$ and antiplatelet agent (clopidrogrel $75 \mathrm{mg} / \mathrm{J}$ ). She stopped herself corticosteroid treatment.

\section{Discussion}

Historically described in Japan, Takayasu arteritis is a rare, large-vessel vasculitis of unknown etiology that most commonly affects women with age under 40 . Worldwide estimates are at 0.5 - 3 cases per million per year. The disease has a worldwide distribution although it occurs more commonly in Asia [2]. Africa, Japan, South-East Asia, Mexico and Latin America, constitutes the five major geographical poles of this affection [1] [3].

In Africa the largest series have been described in the Maghreb where the incidence is nevertheless imprecise. A study conducted in 2009 collected 378 cases in Tunisia [5]. A Tunisian multicenter retrospective study conducted by Ghannouchi collected 27 cases over a period from 1985 to 2005 [4].

In Morocco, El Asri has collected retrospectively over a period of 11 years, 47 cases of arteritis Takayasu [3].

In sub-Saharan Africa, the prevalence is not known.

Mwipatayi also reviewed the largest number of cases with 272 Takayasu arteritis from South Africa seen between 1952 and 2002. The average age was 25 years (range 14 - 66 years) and $75 \%$ of patients were female. Interestingly, only $8 \%$ of the patients were Caucasian [6].

In Ivory Coast, Konin carried out a retrospective study of 12 cases of Takayasu's disease over a period of 15 years [7] and three cases were described in 1982 by Dano P. [8] and one case in 2010 by Ndongo S. et al. [9] in Senegal.

In addition, there have been occasional case reports of this condition, published from South Africa, Senegal, and Kenya [10] [11] [12].

These data do not represent the reality of the incidence of Takayasu disease in our country probably due to the ignorance of the disease by practitioners and the lack of an adequate technical platform. It still represents the first nigerien cases reported in the literature.

In our series, three cases were listed including two women and one man.

Formerly known as the disease of women without pulse, Takayasu's disease has a female predominance marked between 62\% - 97\% according Quemeneur [13]. The sex ratio is between 5 - 12 and could be at the base of distribution of vascular lesions. Indeed, thoracic aorta and its branches were more common among females, males had a tendency toward involvement of the abdominal aorta and its branches [14].

Lupi-Herrera [15] reported in a retrospective study of 107 patients a predominance of women with a sex ratio of $1 / 8.5$. In our series, the three cases are divided into two women and one man. The reason for this female predominance 
of Takayasu's disease remains unknown.

Takayasu's disease is a disease of the young subject occurring during the $2^{\text {nd }}$ or $3^{\text {rd }}$ decade. The age of less than 40 years is also a major criterion for diagnosis [4], but 1 to 2 in 10 patients would be over 40 at the time of diagnosis [13]. The time between the first symptoms and the diagnosis is very variable.

In our series, the age of the three patients at diagnosis was 27 years for the first, 33 years for the other two.

The main modes of revelation of the disease in our series were general signs (100\%). It is similar to a Turkish series with $71 \%$ of cases [16].

These data contrast, however, with the $29.6 \%$ of a Tunisian series, in which the ischemic signs were the predominant mode of revelation $81.5 \%$ [17].

Cardiac signs are found in $30 \%-40 \%$ of cases and are considered as one of the criteria of severity of the disease [5].

The most commonly reported signs are pulse abolition, blood pressure asymmetry, vascular murmurs [17], valvulopathy, arterial hypertension. Cases of coronary artery disease [5] and heart failure are also noted [18].

In all our three observations, the clinical examination notes an abnormality of at least one peripheral pulse (100\%) and one vascular murmur and two patients with asymmetric blood pressure. A digital necrosis is in a patient.

In a series of 107 patients, Lupi-Herrera [15] found concordant figures with the main clinical manifestations: peripheral pulse reduction in $96 \%$ of cases, vascular murmur in $94 \%$ of cases and blood pressure asymmetry in $72 \%$ of cases.

Neurological signs are not uncommon during Takayasu's disease.

Stroke is unusually inaugural. Only a few cases have been reported in the literature [16] [18] [19] [20] [21].

The late and rare occurrence of this complication could be explained by the chronic course of the disease.

Behavioral disorder is a form of expression of the disease, the literature reports the case of a 28-year-old woman hospitalized in 1939 in the Tokyo Hospital Department of Psychiatry for delirium [22]. One of our patients presented behavioral disorders such as acute delusional psychosis that required haloperidol in 2015.

No biological sign is specific. Most often there is a disturbance of the inflammatory balance [4]. Sedimentation rate is often increased in $78 \%-85 \%$ of cases, more frequent at the beginning than at the time of diagnosis [13]. Anemia is also noted in almost $50 \%$ of cases [13].

When Takayasu arteritisis suspected, ultrasound-Doppler has an essential place in the diagnostic approach by allowing the detection of lesions of the supra-aortic trunks, the aorta under diaphragmatic, renal arteries, digestive and iliac, which result in a homogeneous and circumferential thickening of the arterial wall suggestive of inflammatory involvement [23] [24].

CT angiography and MRI, although more expensive, allow a more precise study of the arterial wall by highlighting the parietal edema which is correlated with the activity of the disease [4] [24]. 
By new imaging techniques, and changes but also to a better knowledge of the disease, the diagnosis of the disease was made during the pre-occlusive stage.

The radiological investigations carried out in our study were different according to the availability of the different radiological exams available.

Thus, a CT angiogram arteriography is performed in two of our patients and all three have benefited from Doppler ultrasound (Doppler supra-aortic trunks). The CT angiogram was performed in Morocco.

The lesions observed were constantly stenosis or occlusion. It is the same for El Asri series [3]. Thrombosis lesions were observed in two of our patients, affecting at least one arterial segment.

The most frequently found location in our study was supra-aortic trunks in all three patients.

The frequency of this attack has been noted by all authors even if the percentages are variable:

- $79 \%$ in Morocco [3];

- $56 \%$ in Turkey [25].

In order of frequency, subclavian artery involvement being predominant, is similar to data in the Moroccan series (63\%) [3].

The other disorders of the supra-aortic trunks are: left and right common carotid in the same patient, brachiocephalic artery in one patient. Of the 4 subclavian arteries affected, 3 had stenosis and the fourth had partially occlusive thrombosis. The left and right common carotid arteries have respectively thrombosis and partial stenosis in one case.

The carotid involvement was seen in $66 \%$ of case of El Asri study [3]. Stenosis of the axillary artery was noted in one case.

No cases of coronary insufficiency, heart failure or aneurysmal lesions have been observed.

There is currently no consensus on the therapeutic management of Takayasu's arteritis.

Medical treatment (including corticosteroids, immunosuppressive agents and biologicals), percutaneous transluminal angioplasty and revascularization surgery constitute the therapeutic armamentarium.

The immune mechanism is involved in lesion of the arterial wall explain the positive effect of glucocorticoids and other immunosuppressive agents on the disease especially in the active phase of the disease.

Glucocorticoids are the first line of medical treatment for Takayasu's disease. They are initially given at high doses for one month and then the reduction of corticosteroid therapy is started and stop to a minimal dose (usually $5 \mathrm{mg} / \mathrm{d}$ ) that would be maintained until remission [4] [26].

It has shown efficacy with a success rate of $20 \%-100 \%$ but only $60 \%$ to $80 \%$ of patients treated with corticosteroids alone cure [27].

However, in $50 \%$ of cases, the disease seems insufficiently controlled under steroid therapy alone, and a relapse occurs during the reduction [28].

In addition, HLA type is involved in the pathogenic mechanism of Takayasu's 
disease and in the response to steroid treatment.

Thus HLA A24-B52-DR2 is associated with an accelerated progression of inflammation and a tendency to increase steroid resistance.

In the event of relapse or corticosteroids resistance, second-line immunosuppressive therapy is recommended [29].

There is no randomized control study comparing the efficacy of different immunosuppressive therapy. Methotrexate is the most widely used immunosuppressive agent despite the lack of evidence of its superiority over other immunosuppressive therapy [26].

Hoffman et al. report cases of 16 patients treated with corticosteroids associated with methotrexate, 13 patients have remission and 8 cases (50\%) have 18 months remission [14] [26].

The other immunosuppressive agent used is azathioprine which was evaluated in an Indian study that involved 65 patients who had not received other immunosuppressive agents before. The dose given is $2 \mathrm{mg} / \mathrm{kg} /$ day associated with glucocorticoids for one year. This treatment decrease acute phase proteins. There are no adverse effects reported and angiography control showed the absence of progression of vascular lesions [26].

And in case of refractory disease, despite dual therapy (conventional corticosteroids associated to immunosuppressive agents), biotherapies (anti-TNF $\alpha$, tocilizumab, abatacept, ustekinumab, rituximab) are indicated in combination with corticosteroids and appear to be promising [29] [30] [31].

The Italian Society of Rheumatology does not recommend using biotherapies as monotherapy and don't indicates their use in first line treatment [29].

The three patients in our study were treated with prednisone alone $1 \mathrm{mg} / \mathrm{kg} / \mathrm{day}$ for one month before starting the reduction. They are combined with antiplatelet agent and/or anticoagulants.

Despite a well-conducted medical treatment, revascularization procedures are sometimes necessary due to stenosis and vascular occlusion. They needn't be performed in the acute inflammatory phase of the disease for both angioplasty and conventional surgery.

Stenosis intervention is necessary if there are downstream repercussions, thrombosis or severe clinical expression [13]. In the Mayo Clinic series of 126 patients (recorded between 1984-2009), Rochester [14] evaluated the intervention outcomes of 66 patients with stenosis and occlusion (81\%) and aneurysm (17\%) lesions. A total of 119 procedures (surgery 78\%, angioplasty 22\%) were performed in 66 patients. The most common sites in the surgical group were the aorta (28\%), the carotid arteries (23\%) subclavian (22\%) and renal (16\%) while in the angioplasty group the subclavian arteries predominated (35\%), renal (19\%) and aorta (19\%).

During an average follow-up of about 6 years, the frequency of early complications (restenosis, hemorrhages, stroke) was similar in both groups (15\% surgery and $16 \%$ angioplasty).

At 10 years, follow-up revealed 34 late complications (44\%) in the surgical 
group and 10 late complications in the angioplasty group (66\%) [14]. Restenosis were the most frequent late complications observed.

In our study, two of the three cases had revascularization procedures.

Current treatments for Takayasu's disease have significantly improved patient survival. This survival rate is variable according to the series. Miyata reports a survival rate of $73.5 \%$ at 20 years.

\section{Conclusions}

Takayasu's disease is a non-specific chronic inflammatory panarteritis of unknown etiology.

We report three clinical cases that allowed us to carry out a review of the literature on the clinical, biological, radiological and therapeutic aspects of this pathology poorly known in Niger. The diagnosis is based on clinical, biological and imaging criteria.

The clinical, radiological and therapeutic data of our patients are consistent with the literature data.

Nevertheless, our observations are distinguished by certain peculiarities, such as case 2 revealed by an ischemic stroke and the frequency of arterial thrombosis in two of our three patients.

\section{Conflicts of Interest}

The authors declare no conflicts of interest regarding the publication of this paper.

\section{References}

[1] Jennette, J.C., Falk, R.J., Bacon, P.A., Basu, N., Cid, M.C., Ferrario, F., Flores-Suarez, L.F., Gross, W.L., Guillevin, L., Hagen, E.C., Hoffman, G.S., Jayne, D.R., Kallenberg, C.G.M., Lamprecht, P., Langford, C.A., Luqmani, R.A., Mahr, A.D., Matteson, E.L., Merkel, P.A., Ozen, S., Pusey, C.D., Rasmussen, N., Rees, A.J., Scott, D.G.I., Specks, U., Stone, J.H., Takahashi, K. and Watts, R.A. (2013) 2012 Revised International Chapel Hill Consensus Conference Nomenclature of Vasculities. Arthritis \& Rheumatism, 65, 1-11. https://doi.org/10.1002/art.37715

[2] Watts, R.A. and Scott, D.G. (2014) Epidemiology of Vasculitis. In: Ball, G.V. andFessler, B.J., Eds., Oxford Textbook of Vasculitis, 3rd Edition, Oxford University Press, Oxford. https://doi.org/10.1093/med/9780199659869.003.0002

[3] El Asri, A., Aouni, M., Adnaoui, M., Mohattane, A., Bensaid, Y. and Maaouni, A. (2002) Takayasu Disease in Morroco. 47 Observations. La Revue de Médecine Interne, 23, 9-20. https://doi.org/10.1016/S0248-8663(01)00510-0

[4] Mirault, T. and Messas, E. (2016) Takayasu Arteritis. La Revue de Médecine Interne, 37, 223-229. https://doi.org/10.1016/j.revmed.2015.12.024

[5] Bouzerda, A. and Khatouri, A. (2016) Cardiac Manifestations of Takayasu's Disease Observation and Review of Literature. The Pan African Medical Journal, 24, 82. https://doi.org/10.11604/pamj.2016.24.82.9320

[6] Mwipatayi, B.P., Jeffery, P.C., Beningfield, S.J., Matley, P.J., Naidoo, N.G., Kalla, A.A. and Kahn, D. (2005) Takayasu Arteritis: Clinical Features and Management: 
Report of 272 Cases. ANZ Journal of Surgery, 75, 110-117. https://doi.org/10.1111/j.1445-2197.2005.03312.x

[7] Konin, K.C., Adoh, A.M., Coulibaly, I., KouassiAevouelie, F., KacouAnzouan, J.B. and Kramoh, E. (2002) Takayasudisease in Black African: Clinical and Radiological Aspects. Cardiologie Tropicale, 28, 59-63.

[8] Dano, P., Dérosier, C. and Renambot, J. (1987) Takayasu Disease, 3 Cases in Senegal. Dakar Medical, 27, 397-406

[9] Ndongo, S., Diallo, S., Tiendrebeogo, J., Diop, I.B., Tall, A., Pouye, A., Ka, M.M. and Diop, T.M. (2010) Systemic Vasculitis: Study of 27 Cases in Senegal. Médecine Tropicale, 70, 264-266.

[10] Guidozzi, F., Louridas, G., Grant, M.G., Koller, A.B., King, P. and Naylor, S. (1991) Takayasu's Arteritis in a Pregnant Woman. A Case Report. South African Journal of Surgery, 29, 159-160.

[11] Oguntona, S.A. (2010) Takayasu's Disease in a Young Black Boy. Nigerian Journal of Clinical Practice, 13, 467-469.

[12] Fielder, J.F. (2004) A 23-Year-Old Woman Admitted to Kijabe Mission Hospital with Bilateral Lower Extremity Gangrene. Medscape General Medicine, 6, 56.

[13] Quemeneur, T., Hachulla, E., Lambert, M., Perez-Cousin, M., Queyrel, V., Launay, D., Morell-Dubois, S. and Hatron, P.Y. (2006) Takayasu Arteritis. La Presse Médicale, 35, 847-856. https://doi.org/10.1016/S0755-4982(06)74703-0

[14] Seyahi, E. (2017) Takayasu Arteritis: An Update. Current Opinion in Rheumatology, 29, 51-56. https://doi.org/10.1097/BOR.0000000000000343

[15] Lupi-Herrera, E., Sanchez-Torres, G., Marcushamer, J., Mispireta, J., Horwitz, S. and Vela, J.E. (1977) Takayasu's Arteritis. Clinical Study of 107 Cases. American Heart Journal, 93, 94-103. https://doi.org/10.1016/S0002-8703(77)80178-6

[16] Hsieh, C. (2015) Stroke as an Initial Presentation of Takayasu's Arteritis. Neurology Asia, 20, 177-180.

[17] Jaafoura, N.G., Khalifa, M., Rezgui, A., Alaoua, A., Jazia, E. B., Braham, A., Kechrid, C, Mahjoub, S., Ernez, S., Boughzela, E., Ben Farhat, M., Letaief, A. and Bahri, F. (2010) Takayasu's Disease in the Center of Tunisia: 27 Cases. Journal des Maladies Vasculaires, 35, 4-11. https://doi.org/10.1016/j.jmv.2009.09.002

[18] Abid-Allah, M., Fadouach, S., Chraibi, N. and Mehadji, B.A. (1999) Cardiac Manifestations of Takayasu's Arteritis: A Propos of 5 Cases. La Revue de Médecine Interne, 20, 476-482. https://doi.org/10.1016/S0248-8663(99)80082-4

[19] Rzigui, L., Brahem, Z., Fatma, N., Zakaria, S.M., Ben Sassi, S. and Hentati, F. (2016) Ischemic Stroke Revealing Takayasu's Disease: A Case Report and a Review of the Literature. Revue Neurologique, 172, A78-A79. https://doi.org/10.1016/j.neurol.2016.01.188

[20] Derouich, I., Messouak, O. and Belahsen, F.M. (2013) Ischemic Stroke Reveals Takayasu's Disease in Three Cases. Revue Neurologique, 169, A79-A80. https://doi.org/10.1016/j.neurol.2013.01.187

[21] Nahantchi, A.A., Ntenga, P., Gaye, N.M., Salahedine, M., Soumeila, B., Banzouzi, F., Diagne, N.S., Ndiaye, M.M. and Ndiaye, M. (2017) Cerebral Infarction Revealing Takayasu's Disease in a Young Senegalese Woman: About a Case. Journal of African Clinical Cases and Reviews, 1, 2-6.

[22] Waem, E., Anderson, P. and Hemmingson, A. (1983) Takayasu's Arteritis: A Hospital Region Based Study on Occurrence, Treatment and Prognosis. Angiology, 34, 311-320. https://doi.org/10.1177/000331978303400504 
[23] Laraki, R. (2008) Takayasu Disease. EMC Angéiologie, Elsevier Masson, Amsterdam, 19-1520.

[24] Alibaz-Oner, F. and Direskeneli, H. (2015) Update on Takayasu's Arteritis. La Presse Médicale, 44, 1-8. https://doi.org/10.1016/j.lpm.2015.01.015

[25] Ureten, K., AkifÖztürk, M., Mesut Onat, A., HalilÖztürk, M., Özbalkan, Z., Güvener, M., Kiraz, S., Ertenli, I. and Calgüneri, M. (2004) Takayasu's Arteritis: Results of a University Hospital of 45 Patients in Turkey. International Journal of Cardiology, 96, 259-264. https://doi.org/10.1016/j.ijcard.2003.07.017

[26] Keser, G., Direskeneli, H. and Aksu, K. (2014) Management of Takayasu Arteritis: A Systematic Review. Rheumatology, 53, 793-801. https://doi.org/10.1093/rheumatology/ket320

[27] Wen, D., Du, X. and Ma, C.S. (2012) Takayasu Arteritis: Diagnosis, Treatment and Prognosis. International Reviews of Immunology, 31, 462-473. https://doi.org/10.3109/08830185.2012.740105

[28] Arnaud, L., Haroche, J., Piette, J.C. and Amoura, Z. (2010) Takayasu Arteritis: A Focus on a Single-Center Series of 82 Patients. REV-MED International, 31, 208-215.

[29] Al-Bishri, J. (2013) Takayasu's Arteritis: A Review Article. British Journal of Medicine and Medical Research, 3, 811-820. https://doi.org/10.9734/BJMMR/2013/3150

[30] Unizony, S., Stone, J.H. and Stone, J.R. (2013) New Treatment Strategies in Large-Vessel Vasculitis. Current Opinion in Rheumatology, 25, 3-9.

https://doi.org/10.1097/BOR.0b013e32835b133a

[31] Mekinian, A., Comarmond, C., Néel, A., Lambert, M., Messas, E., Kahn, J.E., Sibilia, J., Amoura, Z., Cohen, P., Cacoub, P., Fain, O., Saadoun, D., Mirault, T., Hie, M., Berthier, S., Marie, I., Lavigne, C., Vandenhende, M.A., Muller, G., Devillers, H., Abad, S., Hamidou, M., Guillevin, L., Dhote, R. and Godeau, B. (2014) Biotherapies in Takayasu's Disease: A Retrospective French Study. La Revue de Médecine Interne, 35, A79-A80. 